\title{
Terras incapturáveis: notas para pensar autodemarcações indígenas ${ }^{1}$
}

\author{
Luísa Pontes Molina² \\ Universidade de Brasília
}

Resumo: Que tipo de encontro é produzido na conjugação entre, de um lado, as Terras Indígenas (TIs) constituídas sob o regime estatal, e de outro os modos indígenas de entender a terra e de habitá-la? Partindo da ideia de que a terra é central para a condição de autodeterminação ontológica e política dos ameríndios, e de que estes sabem melhor do que ninguém que as suas terras não se resumem às TIs, o presente artigo apresenta uma proposta de abordagem das autodemarcações de terra que questiona diretamente a redução da ação política desses povos à pressão sobre o Estado-nação. Para isso, debate contribuições recentes - como a de Oliveira Filho (2018) - e mobiliza tanto a descrição de experiências de autodemarcação como a produção específica sobre retomadas de terra.

Palavras-chave: Terras Indígenas, autodemarcação, retomadas, demarcação de terras.

${ }_{1}$ Agradeço a leitura atenta e os comentários da professora Susana Viegas a este artigo - a partir dos quais pude apresentar de maneira mais consistente e precisa os argumentos que venho desenvolvendo.

2 Doutoranda (PPGAS/DAN/UnB). lupontesmolina@gmail.com 


\title{
Incapturable lands: notes to think indigenous self-denominations
}

\begin{abstract}
I recover some ideas arising from the ontological turn in anthropology, especially, dialogue with authors like David Graeber, Eduardo Viveiros de Castro and Mauro Almeida. Throughout the essay, in addition to weaving some continuities and ruptures between them, I try to shed light on one question: does the ontological bet on multiplicities necessarily depoliticize?
\end{abstract}

Keywords: Incomensurability; Ontologies; Native policies; Intensive difference.

\section{Tierras inalcanzables: notas para pensar autodemarcaciones indígenas}

\begin{abstract}
Resumen: en este texto, recupero algunas ideas derivadas del giro ontológico en la antropología, especialmente, dialogo con autores como David Graeber, Eduardo Viveiros de Castro y Mauro Almeida. A lo largo del ensayo, además de tejer algunas continuidades y rupturas entre ellos, procuro lanzar luces sobre una cuestión: la apuesta ontológica en las multiplicidades necesariamente despolitiza?
\end{abstract}

Palabras clave: Incomensurabilidad; Ontologías; Políticas nativas; Diferencia intensiva. 

do Sul há pelo menos quatro décadas. ${ }^{3}$ Classificar determinadas iniciativas como "autodemarcações" (para fazer delas objeto de análise) demanda, contudo, o cuidado de uma primeira análise criteriosa: tanto pelos problemas que uma definição preliminar levanta (como o de quem detém a prerrogativa de definir em extensão essas formas de ação politica ou mesmo os coletivos indígenas), como pelo risco de estendê-la demais, esvaziando-a de sentido. Apresento, neste artigo, a síntese de uma proposta de abordagem para esse termo - desenvolvida em maior extensão em minha dissertação de mestrado (Molina, 2017a). Ali, expus um quadro geral com datas e locais de todos os casos de autodemarcação sobre os quais obtive informação, e ainda tratei em maior detalhe de quatro deles: o da TI Sawre Muybu dos Munduruku (PA); o da TI Alto Rio Purus dos Madijá e Huni Kuin (AM); o da TI Kulina do Médio Juruá (AC) e da TI Wajãpi (AP). Mencionarei esse último caso, ainda que brevemente, também neste artigo.

Além de chamar a atenção para o fato de que experiências desse tipo ocorreram em distintos momentos da história do país (contrariando as minhas próprias suposições iniciais e, como veria mais tarde, algumas sugestões de autores que trataram no tema), procurei olhar para as autodemarcações como expressões da força criativa das políticas ameríndias: políticas que se fazem na terra, a partir da terra e pela terra - políticas que são elas mesmas, quem sabe, criações da terra (no sentido de Strathern,2009). E se é na terra que se constituem os coletivos, em seus modos próprios de produzir parentes, de fazer crescer e circular alimento, de realizar rituais, de relacionar-se com os demais seres que ali habitam etc. (terra esta que, como ainda comentarei, não se confunde ao solo ou ao perímetro de uma área), a luta pela terra é sobretudo a luta pela vida e pela garantia da diferença - que tem na terra, antes, a sua condição. Recuperarei aqui, portanto, o argumento de que não é apenas da garantia de sobrevivência numa terra demarcada que se trata a luta - como se sobreviver bastasse e qualquer terra servisse; é, antes, pela existência do coletivo como tal e a persistência de seu modo de vida, indissociável da vida em sua terra, que lutam. Autodemarcação como autodeterminação indígena: eis a potência dessa iniciativa.

\section{Terra de viver}

Em uma primeira mirada, experiências de autodemarcação referem-se ao envolvimento direto de coletivos indígenas com uma determinada etapa do processo de regularização fundiária ${ }^{4}$ de suas terras: a consolidação dos limites físi-

\footnotetext{
3 Há uma produção mais extensa sobre o assunto em outros países da Améria do Sul. Para o contexto venezuelano ver, por exemplo: cf. Jiménez \& Perozo (1994), Zent et. al. (2003), Medina (2003), Tabarez (2011), Zent et. al. (2011) e Morales \& Quispe (2014).

4 A regularização fundiária de terras indígenas, no momento em que este artigo é escrito, está como que suspenso. Cumprindo compromissos de campanha, Jair Bolsonaro tem feito de tudo, desde o primeiro minuto de seu mandato como presidente da República, para desmontar a politica indigenista (transferindo da Funai para o Ministério da Agricultura a competência de demarcar TIs, entre outras medidas), legalizar o arrendamento dessas áreas e a exploração mineral nelas - como parte de um projeto amplo e complexo, do qual não poderei tratar aqui, uma vez que demandaria, por si só, uma discussão de fôlego, em um artigo próprio. Formalmente, as demarcações seguem o que está estipulado no decreto $n^{\circ} 1775$ de 8 de janeiro de 1996 - isto é, um processo em sete fases: (i) estudos de identificação - realizados por um GT sob coordenação de um antropólogo, e cujo produto final é o Relatório Circunstanciado de Identificação e Delimitação (RCID); (ii) aprovação do RCID pela Funai, que publica o seu resumo no Diário Oficial da União (DOU); (iii) apresentação de contestações ao RCID (que devem ser dirigidas à Funai dentro do prazo de 90 dias após a publicação no DOU) e elaboração de pareceres acerca das contestações, pela Funai, dentro do prazo de 60 dias; (iv) deliberação por parte do ministro da Justiça - que pode expedir a portaria declaratória da área e ordenar a sua demarcação ou determinar que se façam diligências no prazo de 90 dias, ou mesmo indeferir a
} 
cos dessas áreas, pela abertura de picadas e fixação de placas de identificação. No entanto, essas experiências estão longe de reduzirem-se à dimensão técnica e a um momento pontual de um processo que, ele mesmo, não é apenas legal ou administrativo, mas também político - como a literatura antropológica não cansa de frisar. Não está no envolvimento político e técnico dos índios, portanto, a especificidade de uma autodemarcação. Em muitos outros processos de criação de TIs, é mesmo a partir de uma reivindicação indígena que o procedimento administrativo se inicia; em outros, há uma atuação também direta dos índios na identificação dos limites da área. E parecem-me poucos, senão inexistentes, casos em que a demarcação não se deu sem muita mobilização pelo pleno reconhecimento dos direitos territoriais indígenas.

Lino Neves (2012) entende a autodemarcação como "a iniciativa contrahegemônica mais eficaz no sentido de questionar o papel centralizador do Estado sobre as questões indígenas"; um mecanismo de pressão que tem como intuito promover alterações no processo de regularização fundiária como um todo (:542). Para o autor, iniciativas desse tipo refletem a visão eminentemente "coletivista" da terra que funda a noção indígena de "terra de viver" - física, cultural e temporalmente contínua, de e para todos. Trata-se, portanto, de "uma visão de terra muito diferente da visão que os brancos têm da 'terra indígena", conclui Neves (:530) - sem contudo aprofundar-se numa discussão sobre como essa visão específica da terra (ou melhor, essa diferença de visões sobre um mesmo 'objeto') permite entender a especificidade, com o perdão da redundância, da autodemarcação. Por fim, essas iniciativas se dão, ainda segundo o autor, na etapa propriamente demarcatória do processo, a partir de convênios assinados entre organizações indígenas e a Funai - distinguindo-se, assim, das "demarcações convencionais" (realizadas por empresas de engenharia e topografia) e das "demarcações participativas", como as que se deram no âmbito do Projeto Integrado de Proteção às Populações e Terras Indígenas da Amazônia Legal (PPTAL) - cujo objetivo era acelerar a regularização de TIs na Amazônia Legal (Mendes 2002:37). ${ }^{5}$

A meu ver, há dois problemas na descrição de Neves. Primeiro, a redução da questão ao plano dos mecanismos de pressão (e a limitação da política à pressão sobre o Estado), ou da busca por garantir, por conta própria, o reconhecimento de direitos - com o respectivo problema da redução da política à reivindicação de direitos. Segundo, a restrição dos casos de autodemarcação àqueles nos quais foram firmados convênios com a Funai. Discuti o primeiro problema com mais fôlego em outro lugar (Molina, 2017b), e o retomo brevemente abaixo. Por ora, tratemos do segundo: talvez por se focar no caso da autodemarcação realizada pelos Kulina no Médio Juruá (ver também Merz 1997), Neves tenha deixado em segundo plano a existência de casos que não se deram através de convênios, como o dos Kulina e Kaxinawá do Alto Purus (que ele chega a citar como a primeira iniciativa desse tipo, mas apenas de passagem), por exemplo. De todo modo, depois da publicação da tese de Neves, diversas outras experiências de autodemarcação foram realizadas por outras vias e em um contexto de notável tensão na relação dos índios com a Funai.

Menos do que querer tirar o crédito do trabalho do autor, pretendo, com essas observações, inserir mais um elemento na análise que proponho fazer aqui, uma vez que a definição de autodemarcação que ora esboço não prescinde,

identificação; (v) demarcação física da área e reassentamento de ocupantes não-índios, quando for o caso43; (vi) homologação da TI pelo presidente da República, por meio de decreto; (vii) registro da TI.

5 Para uma análise mais detalhada acerca das chamadas demarcações participativas, ver o capítulo 9 de Neves (idem), Kasburg e Gramkow (1999) e Gramkow (2002). 
mas parte da relação dessas iniciativas com o conjunto de normas, procedimentos administrativos e agentes implicados na demarcação - isto é, com a regularização fundiária de TIs, um processo e uma categoria que foram criados pelo aparato estatal e pertencem ao seu rol de instrumentos para lidar com as áreas habitadas por índios. Não poderia ser diferente: ainda que haja algo de particular nessas experiências, quando comparadas às demarcações 'convencionais', é mesmo a partir da categoria e do processo jurídico-administrativo estatal que ela se dá, é sobre esse aparato que ela se dobra. O que busco compreender, portanto, é a natureza e a expressão dessa particularidade, para então poder refletir sobre o que ela nos diz acerca dos múltiplos planos de relação que nela estão implicados: entre os conceitos indígenas de terra e a figura da TI; entre os modos indígenas de fazer política e a burocracia estatal; entre as forças do aparelho de Estado e da máquina de guerra indígena.

É fundamental ponderar, portanto, que há uma assimetria no próprio centro desta questão: o 'objeto' dela - as TIs e aquilo que as consolida - pertencem a um regime de significação radicalmente distinto dos regimes indígenas. Seguindo a trilha da discussão desenvolvida por Julia Miras (2015), vemos que essa diferença se expressa, de partida, pelo imperativo de ordenação e dominação do solo, intrínseca à própria conformação do Estado nacional, que age tanto sobre as terras (cuja demarcação estabelece o domínio da terra pela União) como sobre os seus habitantes. A autora mostra que subjacente a esse imperativo, há uma concepção de território como terra dividida, e uma operação de separação entre sujeitos habitantes e objetos habitados - o que, em última instância, eclipsa a capacidade da terra de ser ao mesmo tempo ego e oikos (casa). Nesse ponto Miras segue o argumento de Nodari (2007), de que a noção moderna de propriedade se baseia na divisão entre sujeitos possuidores e objetos possuídos. No caso da terra, essa separação se daria entre sujeitos que habitam e objetos habitados: "algo exterior ao sujeito e não produzido na relação entre múltiplos sujeitos” (Miras, 2015:22).

Para poder ser dividida, dimensionada, mensurada - podendo, então, tornar-se uma abstração e ser dominada -, a terra é cindida, e tanto a sua própria multiplicidade como a multiplicidade de seus "nativos" é obstruída, esvaziada de seu caráter de processo e acontecimento, argumenta Miras (:22). Essas operações limitam a terra a uma forma, dão-lhe fronteiras, fixam seus habitantes, controlam os seus fluxos, submetem-na a uma ordenação do solo e implicam "uma territorialidade específica que envolve um tipo de relação com a terra (...) [e] da imposição de relações de poder, da estratégia de domesticação da terra" (:26). Assim, frisa a autora, ainda que a categoria de TI parta de um reconhecimento acerca da existência de territorialidades diversas, a sua criação se deu (como a sua atualização se dá) como uma forma de o aparato jurídicoadministrativo estatal dar sentido aos modos indígenas de habitar, e também de enquadrar esses povos sob o seu ordenamento, fazendo da terra dinâmica, e de seus fluxos, território estático (:32). No entanto, é importante notar ainda que, para Miras, apesar disso, a demarcação introduz uma possibilidade de reterritorialização após as investidas coloniais que expulsaram os índios de suas terras isto é, como possibilidade, ou alternativa, para a construção de oikos (casa), quando já se consumaram as expropriações e quando os conflitos já foram perdidos (:37). Diz também a autora que mesmo com a imposição da sua forma, a TI pode ainda abrigar em seus limites e sentidos outras "terras" e ontologias. Para tal, é necessário investir em um processo de constituição de cada terra indígena "que contemple os lugares do passado e do presente, mas que também 
permita a eles [índios] um futuro", possibilitando a emergência de novas territorialidades (:33).

\section{Uma passagem pela experiência wajãpi}

A descrição que Dominique Gallois faz da demarcação da TI Wajãpi ${ }^{6}$ se conecta notavelmente à discussão de Miras e ao que ainda argumentaremos, acerca da tradução das terras indígenas em TIs. Apresentei também os casos das TIs Alto Purus, Kulina do Médio Juruá e Sawré Muybu (dos povos Kaxinawá, Kulina e Munduruku, respectivamente, sendo que a primeira é também kulina) na pesquisa de mestrado supracitada, articulando o histórico da regularização fundiária dessas áreas ao que os materiais analisados (processos da Funai, relatos e cartas) permitiram ver a respeito dos efeitos da ação indígena sobre esses processos e vice-versa. Considerando o limite de espaço deste artigo, resumirei a exposição ao material wajãpi e a alguns aspectos de um processo que se estendeu por cerca de 20 anos.

. Localizada nos municípios de Laranjal do Jari e Pedra Branca do Amapari, no estado do Amapá, essa TI teve os seus primeiros contornos traçados por um antropólogo e retraçados por um sertanistas, ambos em 1976 - apenas três anos depois do contato desse povo com a Funai (e menos de uma década depois dos primeiros contatos com não-indígenas), num período marcado pelos impactos da construção da rodovia Perimetral Norte (BR 210) e pela presença maciça de garimpeiros nos domínios indígenas (Gallois, 2011:39). Mais cinco propostas de área seriam apresentadas à Funai até o ano de 1991, quando uma portaria do Ministério da Justiça declarou a posse permanente indígena nos seus perímetros, junto à determinação para que se realizasse a demarcação dos 573mil hectares da sua área (id.:45). Esta foi realizada entre 1994 e 1996, em uma iniciativa considerada pioneira, uma vez que os Wajãpi tiveram um marcado protagonismo - fazendo a demarcação física dos limites da TI em si e estabelecendo as 'diretrizes' do trabalho (id:47) - e que as atividades se desenvolveram em um convênio estabelecido entre a Funai, a agência de cooperação alemã GTZ e o Centro de Trabalho Indigenista (CTI).

Firmado em 1995, esse convênio se insere no quadro mais amplo das experiências de "demarcação participativas", que acompanharam a ampliação do Programa de Demarcações do PPG7, e a consolidação do PPTAL. A experiência, conta-nos Gallois (apud Krasburg \& Gramkow, 1999), foi determinada pelo processo de controle territorial que os Wajãpi vinham desenvolvendo desde a década de 1980 (:139), e tomou como princípio o modo específico desse povo ocupar a terra, marcado pela dispersão (:150). Os trabalhos, diz ainda Gallois em outro lugar (2011), foram divididos em seis etapas: identificação das cabeceiras dos rios limítrofes, realizada "sob responsabilidade exclusiva dos Wajãpi, organizados em diferentes equipes" (:51); levantamento geodésico, feito por técnicos ligados a empresas e a universidades e acompanhados por um grupo wajãpi numeroso; plaqueamento de toda a extensão do rio Inipuku e de sua embocadura no rio Jari - que "constituiu uma visita de rememoração da história do grupo"

${ }^{6}$ Há algo curioso nesse caso: embora os Wajãpi não tenham chamado o processo de "autodemarcacão", este foi até muito recentemente o exemplo mais conhecido desse tipo de iniciativa - considerando o envolvimento direto do coletivo indígena nas ações não só de demarcação física como de monitoramento dos limites. Esse caso está exposto aqui porque - repito - a identificação como "autodemarcação" ou "demarcação participativa" é menos importante do que a descrição de como os índios viveram esse processo. 
(:52); abertura de picadas nos limites secos; demarcação do divisor de águas Ari-Pakwarã e plantios agro-florestais nas picadas (id.:ibid.).

Como veremos com as narrativas acerca dessa empreitada, os efeitos da criação da TI e a sua sobreposição à terra se dão em diferentes direções, extrapolando o encontro ou confronto entre as agências indígenas e estatais, e sendo também vividos como experiências na terra. Nos percursos das expedições demarcatórias são revistos caminhos e paragens do tempo dos antigos, passam-se a ser conhecidos locais dos quais só se tinha um vago conhecimento. É o que conta Siro, uma liderança wajãpi, acerca da expedição até a cabeceira do rio Kumakary. Em sua fala aparece um leque de lugares distintos: aqueles que haviam sido morada do criador dos Wajãpi; outros, percorridos no passado pelos antigos; lugares de pouso e, enfim, a cabeceira propriamente dita, que é apresentada por ele com generosos detalhes. "Chamamos os lugares como esse de Janejarã tapererã. Não tem árvores, só capim. (...) Não tem palmeira warakuri, nem kurua, nem mumuru" - e a extensa lista do que não há ali segue (Gallois, 2011:54). Conta Siro também que ao chegarem ali, os índios se surpreenderam com o sereno, que desafiava qualquer iniciativa de manter acesa uma fogueira durante a noite: "os antigos sabiam que fazia frio por lá, mas nunca haviam falado do sereno" (Id.:ibid.). Ainda sobre esse ponto - mas agora no curso baixo do rio Visagem, onde "não tem rastro de branco na mata", pois estes "só andam de motor" -, Kurapi’a, outra liderança wajãpi, fala: "existem muitas capoeiras dos antigos na cabeceira (...). Pra baixo, só existe um caminho dos antigos. Não o vi desta vez, mas já o percorri há muito tempo atrás" (id.:55).

Além de rever ou conhecer lugares, torna-se também possível atualizar a relação com locais já percorridos - fazendo surgir, inclusive, novos nomes. É o que se vê no relato de Parikura, liderança wajãpi, a respeito das cachoeiras do rio Felício: "Durante esta expedição, nós demos um novo nome àquela cachoeira: é Tare'y kai ytu, a cachoeira do trairão queimado, porque Pejanã queimou o peixe que íamos comer" (Gallois, 2011:56). Algo semelhante aparece na fala do chefe Waiwai sobre diferentes locais da expedição para a cabeceira do igarapé Pakwarã; nela, vemos uma série de lugares recém-nomeados a partir da experiência da própria expedição:

\footnotetext{
chamamos o lugar de Pinoru tetã, o abrigo de folha de bacaba, porque não tem palha preta. (...) Então, dormimos no lugar que chamamos Murumuru tetã, o abrigo de murumuru. Um lugar muito difícil, onde não tem palha pra cobertura. (...) Depois, levamos o caminho até um lugar que chamamos Yjysõwa, o lugar da argila roxa. A argila é bem roxa, azul mesmo Demos esse nome (id.:58).
}

É interessante notar, ainda que de maneira aproximativa, como a demarcação - um processo de metrificação do espaço (no sentido de Nodari, 2014) por definição - não só é permeada como também engendra experiências outras, que não aquelas de estabelecer fronteiras ou de estar contido em um espaço, como se dá com o limite métrico. Tomemos também como exemplo a fala da liderança wajãpi Tapenaiky sobre uma expedição rumo à cabeceira do igarapé Y’yakã, um dos limites da área indígena. Conta ele que os seus parentes até então não conheciam esse lugar; "não sabiam que era o Y’yãkã, iam caçar por ali, mas não sabiam. Meu pai sabe. Ele já tinha andado por ali há muito tempo, pra caçar, por isso que sabia que a cabeceira era por ali" (Gallois, 2011:57). Estaria o processo de demarcação - ao fazer com que as pessoas voltassem a percorrer lugares ou passassem a conhecê-los, e que eventos ocorram novamente neles - reanimando os lugares, trazendo-os "de volta à vida" (como discute Coelho de Sou- 
za (2009), a partir das experiências kisedje, e também Cardoso (2016) seguindo Ingold (2000)), ou atualizando a sua vida na experiência presente?

Ainda sobre os efeitos do processo de demarcação, observemos o que discute Gallois (2000, 2004, 2007), acerca das transformações nos conceitos de terra e povo - ou de uma "auto-representação étnica" (para usar os termos da autora) - entre os Wajãpi nos contextos de defesa da sua área contra invasões e de reivindicação da TI. Conta a autora que até os primeiros anos da década de 1970, quando a Funai reuniu em um posto de assistência os Wajãpi sobreviventes da forte epidemia de sarampo decorrente da invasão de garimpeiros na região do Amapari, predominava uma "auto-representação não centralizada”, ligada a uma forma de organização e de ocupação territorial em "zonas de suporte do "modo de ser fragmentado" do grupo local, conta ainda Gallois. Essa forma de ocupação marcada pela dispersão de pequenas aldeias em torno de lugares centrais (2011:21) e fundamentalmente ligada ao grupo local toma expressão no termo ekowa, que designa o lugar onde um indivíduo vive ao seu modo (2004:6). É apenas no contexto de emergência da categoria "nós Wajãpi” - um contexto marcado pelo contato com não-índios, ainda segundo Gallois - que surge também uma expressão para identificar a "nossa terra", jane yvy. Em outras palavras, "só há terra [no sentido de TI] se há 'Wajãpi”" (2000:4).

Por fim, e ainda no que diz respeito aos efeitos das transformações e traduções promovidas pelo processo de demarcação, vale mencionar uma anedota apresentada por Gallois sobre o contexto da instalação dos marcos da área wajãpi. Expressão direta dos equívocos que atravessam a criação de uma TI, essa anedota e o comentário subsequente de Gallois iluminam o argumento que apresentei anteriormente sobre a não dissolução do conceito indígena de terra com a criação da TI, a sua diferença em relação à concepção não-indígena e a incomensurabilidade que pauta esse encontro.

\footnotetext{
Aldeia Taitetuwa, num dia de festa. (...) Os anfitriões terminaram de limpar a praça, onde em breve todos vão dançar. Matapi, chefe da aldeia, chama seus netos: eles devem retirar o marco de cimento que ocupa o centro da praça de dança. Seis crianças extraem da terra o pesado marco, com ajuda de alavancas e, já sem forças, o deixam cair na borda do terreiro. Será recolocado no seu lugar no dia seguinte, sob os cuidados do chefe. (...)

A aldeia Taitetuwa foi, efetivamente, uma das primeiras visitadas pela equipe de geodesia responsável pelos cáculos da demarcação física da Terra Indígena e, sem conhecer ainda o modo de vida dos Waiãpi, decidiu fincar a peça bem no centro da praça. $\mathrm{Na}$ perspectiva dos engenheiros este era o ponto ideal para o marco, que deveria ser apropriado como um monumento, em torno do qual a aldeia poderia crescer, como qualquer povoado (Gallois, 2000:1).
}

\section{Terras incapturáveis}

O termo "autodemarcação" expressa uma curiosa conjugação: por um lado, sabemos bem - e os índios sabem melhor do que ninguém - que o modelo de TI (seus limites próprios e particularmente construídos, sua ingerência sobre a ocupação da terra, a política de gestão e administração a ela ligada etc.) é alienígena às formas indígenas de habitar e às dinâmicas dos grupos locais de relacionarem-se uns com os outros e com os demais Outros da região. Por outro lado, uma terra propriamente indígena não é, por definição, uma terra qualquer - e o problema reside, justamente, na constituição de um entendimento sobre $o$ que ela é: algo que a partir do ordenamento jurídico se tenta descrever sob a no- 
ção de "ocupação tradicional" e com um arsenal próprio de procedimentos administrativos. Olhemos mais atentamente para a "curiosa conjugação" (ou, como buscarei argumentar, uma dissonância) sinalizada acima: que tipo de encontro é promovido - e o que permanece, por assim dizer, 'incapturável'?

Após um período de marcante embate entre posições pró e anti-indígenas - em que se reivindicava, respectivamente, as expressões "terras [simplesmente] ocupadas" e "terras permanentemente ocupadas" (Barreto Filho, 2005: 121) -, a Assembleia Nacional Constituinte consolidou a formulação ora vigente de "terras tradicionalmente ocupadas" no seu capítulo dedicado aos índios. Esse "advérbio ambíguo", como o qualifica Barreto Filho, ao transitar "entre o tempo e o modo", reúne "a ideia de imemorialidade e a noção de modo de ocupação" (id.: ibid.), um contraste com o qual os esforços de identificação de TIs teriam que lidar dali para a frente. Essa ambiguidade - resultado do baixo investimento em qualificar as noções de "ocupação" e de "tradicionalidade” - já era notada, aliás, na época da formulação do artigo 231 da Constituição Federal de 1988. É o que mostra Sandra Nascimento (2016:115), que então argumenta:

\begin{abstract}
Ao estabelecer o direito à posse permanente das terras que tradicionalmente ocupam, condicionando a elementos objetivos para configurar o âmbito do tradicional, o agente constituinte, propositalmente, renomeou, mas não ressignificou o conceito relativamente ao núcleo jurídico da posse no direito civil clássico, em relação à exteriorização dela. A comprovação ficou dependente da valoração de fatos. Estes devidamente valorados desencadeiam a consequência jurídica que é o reconhecimento do direito. A natureza vaga desse núcleo normativo demonstra a manobra linguística para, de alguma maneira, manter-se o controle sobre a questão indígena. (id.:120. Ênfases acrescentadas)
\end{abstract}

Sem desconsiderar a importância e mesmo a necessidade de discutir o contexto de elaboração desse texto constitucional, procuro aqui me ater ao problema da "valoração de fatos", como Nascimento aponta acima; isto é: o entendimento traçado no artigo 231 dos elementos pertencentes às "terras tradicionalmente ocupadas pelos índios". Estes, expostos no parágrafo $1^{\circ}$ daquele artigo, podem ser divididos em quatro 'critérios' ou 'parâmetros' a serem aferidos: (i) a característica permanente da habitação; (ii) a 'utilização' da terra para atividades produtivas; (iii) o caráter imprescindível da terra para a preservação dos recursos necessários ao bem-estar dos povos que as habitam; e (iv) a preservação, pela terra, da reprodução física e cultural desses povos "segundo seus usos, costumes e tradições”. Dominique Gallois entende esses elementos como expressões de "quatro dimensões distintas, mas complementares, que remetem às diferentes formas de ocupação, ou apropriações indígenas de uma terra" (2004:37, ênfases acrescentadas). Uma interpretação apressada, a meu ver, pois nos levaria a supor a preeminência de alguma estabilidade, uma espécie de 'encaixe' entre o texto do artigo constitucional e a multiplicidade de realidades que ele busca abarcar; como se o primeiro fosse uma descrição dessas realidades - o que permitiria falar que ele remete a formas de ocupação. Acredito que é mais proveitoso dar um passo atrás, questionando essa estabilidade e atentando para o próprio encontro entre as disposições da Constituição - junto às normas que a elas seguiram - e essas formas de ocupação, com aquilo que as permeia: ontologias indígenas e seus respectivos conceitos de terra, seus modos de habitar e de constituir lugares, e tanto mais.

Ao voltar-se para os seus materiais etnográficos, a própria discussão de Gallois nos permite desconstruir a suposição desse encaixe estável. Comentando a incumbência do antropólogo responsável pelos estudos para a criação de TIs de mostrar como, em cada caso, as "lógicas espaciais" indígenas se articulam 
com essas "dimensões", a autora problematiza o esforço, suposto nessa incumbência, de "tradução" - usando um termo mobilizado por Leite (1999:130) para discutir a identificação de TIs que será especialmente útil para a discussão que segue. É sobre o caso da TI Zo'é (cuja identificação e delimitação foram feitas por ela mesma e por Nadja Havt, a partir dos conceitos de território e modo de vida, elaborados por esse povo) que Gallois se apoia, mostrando como é inadequada, naquele contexto, a aplicação 'seca' da noção de "habitação permanente". O padrão de ocupação territorial dos Zo'é, conta-nos ainda Gallois, alterna entre movimentos de dispersão e de concentração populacional: "um princípio que rege a qualidade de vida do grupo, abrangendo desde as relações interpessoais entre famílias e entre grupos locais, até aquelas mantidas com os não-Zo'é”. (2004:38). A definição da área de ocupação histórica desse povo - que necessariamente expressará uma sobreposição entre áreas diferentes de grupos locais também distintos - parte diretamente desse padrão, o que implica reconhecer as suas descontinuidades territoriais (id.: ibid.).

$\mathrm{O}$ argumento de Gallois se desdobra ainda nos efeitos que a consolidação de uma TI (ou de uma "terra" - termo equivalente a TI na exposição da autora) tem sobre a "territorialidade" indígena - isto é, sobre a relação de cada povo com o seu território. Este, para a autora, concerne "à construção e à vivência, culturalmente variável, da relação entre uma sociedade específica e sua base territorial" (id: 39). Gallois ainda discute etnograficamente os efeitos da constituição da TI a partir das transformações observadas entre os Wajãpi nos contextos de contato interétnico e no próprio processo de regularização fundiária, para então ponderar que

Teríamos então de analisar, caso a caso, as respostas dos grupos indígenas à conversão de seus territórios em terras, uma vez que, como sugere João Pacheco de Oliveira: "Não é da natureza das sociedades indígenas estabeleceram limites territoriais precisos para o exercício de sua sociabilidade. Tal necessidade advém exclusivamente da situação colonial a que essas sociedades são submetidas" (1996: 9). Na transformação de um território em terra, passa-se das relações de apropriação (que prescindem de dimensão material) à nova concepção, de posse ou propriedade (id.: ibid. ênfases acrescentadas).

Ainda que a ideia de 'apropriação' demande uma avaliação mais cuidadosa (sobretudo para tratar de relações com a terra), ou por mais que a passagem para um regime de posse ou propriedade, com a instituição de uma TI, seja algo questionável, pretendo apenas reter aqui, para os fins da argumentação que ora esboço, a ideia de que a demarcação promove transformações nos modos indígenas de habitar a terra e de relacionar-se com ela - transformações essas que geram "respostas" (termo tímido, que poderíamos talvez estender para 'reação', ou mesmo 'impacto'). Além disso, e lançando mão de uma licença, digamos, interpretativa para ler a citação de João Pacheco de Oliveira apresentada por Gallois, podemos pensar o problema das "respostas" indígenas a tais transformações como tendo 'impactos' sobre a territorialidade desses povos, uma vez que os modos deles relacionarem-se com a terra não se encerra na natureza; não é, por assim dizer, natural - como não o é a relação do 'nativo' com a sua 'cultura' (Viveiros de Castro, 2002:114).

Por falar em natureza, e voltando para os critérios estipulados pelo $\S 1^{0}$ do Artigo 231, merece atenção a preeminência dada ali às "atividades produtivas", à “preservação dos recursos ambientais" e à "reprodução física e cultural” dos índios - que nos impõe desafios próprios para a descrição dos modos desses povos relacionarem-se com a terra e da centralidade desta para suas ontologias. Como, portanto, não equacionar a cultura à natureza desses povos e, assim, en- 
cerrar a terra a um outro registro de 'natureza', mais próximo da ideia de 'recurso', isto é, um objeto separado, um meio para que essa relação 'natural' com a cultura se dê? Consequentemente, estaria esse equacionamento e a ênfase na reprodução seguindo uma concepção já bastante debatida de que os índios estariam sujeitos aos imperativos da subsistência - isto é, da mera existência?

Não me refiro ao que poderia ser identificado com uma esfera propriamente econômica das socialidades indígenas, mas a uma ideia tácita, atrelada à de 'reprodução', de que existir basta - quando sequer sabemos o que é 'existir' para esses povos. "Primeiras sociedades do lazer, primeiras sociedades da abundância”, diz Marshall Sahlins, recuperado por Pierre Clastres (2003:209) em sua argumentação contra a determinação negativa dessas 'sociedades' - que produziriam apenas o necessário para viver, seja por incapacidade técnica, seja por preguiça. Mas há outra coisa em jogo; "misteriosamente, alguma coisa existe na ausência”, como dizia também Clastres (id.:41). Ao nos colocarmos no espaço fértil da pergunta, concebendo o desencaixe, a diferença conceitual, abrimos espaço para os outros, como dizem Pignarre e Stengers (citados em Viveiros de Castro, 2011:314). Como não fazê-lo, considerando que contínua e constantemente, de norte a sul do país, os índios têm chamado a atenção para o caráter indissociável da relação entre a garantia à vida e a permanência na terra?

“[A] terra ocupada é uma 'terra de viver", afirma Lino Neves (2012:524) acerca dos múltiplos, diversos e complexos sentidos abarcados pela noção de vida aí contida. A essa constatação o autor une o argumento de que a expressão "território de reprodução física e cultural" revela-se indiscutivelmente mais ampla quando confrontada pelas realidades que ela busca descrever. Neves então conclui que a reivindicação de uma TI não poderia jamais dizer respeito a uma "terra qualquer" - apresentando um contrapondo fundamental à ideia de que ela se encerraria no registro da exploração de recursos (id.: ibid.). Para além dos problemas políticos de resumir as ontologias indígenas aos ditames da necessidade e da reprodução, portanto, a noção de 'subsistência' está longe de definir o que a terra é para os ameríndios - o que tampouco é capturado pelo que a categoria de "ocupação tradicional" busca abarcar. Ou seja: há um encontro desencontrado aí - um ruído, uma disjunção; como, então, pensar a partir (e não apesar) da disjunção?

\section{Dissonância de mão dupla}

Se é sobre o aparato estatal que conforma a TI (categorias, normas e processos) que a autodemarcação se realiza, e se há, como vimos, uma assimetria central nas operações que consolidam essas experiências, a particularidade delas que me interessa tratar aqui está nas relações da qual partem (entre os distintos conceitos de terra) e nas novas relações que elas estabelecem (entre os índios e o Estado, grosso modo). A autodemarcação parece promover mesmo uma dobra sobre o aparato estatal, uma tensão que se dá não exatamente no plano da execução dos procedimentos (estes são mantidos, já que estão no cerne de tal aparato e, portanto, do lado 'majoritário' da assimetria) ${ }^{7}$, mas no dos conceitos que os subjazem. Ou melhor: a tensão sobre o aparato estatal é exercida, antes, no âmbito dos conceitos, expressando-se então no dos procedimentos -

\footnotetext{
7 Observemos, por exemplo, a ênfase dada ao rigor técnico no caso da autodemarcação da TI Kulina do Médio Juruá (cf. Merz 1997), ou a exposição de Gallois (2011) sobre o protagonismo dos Wajãpi na realização dos procedimentos técnicos durante a demarcação de suas terras.
} 
onde ela é mais percebida, por assim dizer, como é percebido o desconcerto, ou a instabilidade, a partir de acordes dissonantes em uma harmonia.

O encontro que a autodemarcação promove - uma dissonância de mão dupla, como me inspira a pensar o sentido geral que a teoria da música dá ao termo - é, pois, eminentemente instável: pois tanto é desconcertante a adoção mesma desse aparato conceitual-procedimental-normativo estatal por parte dos índios, como o são as imposições (técnicas e normativas) que esse mesmo aparato apresenta aos índios para que a 'adoção' funcione. Trata-se portanto de um encontro tão instável quanto irredutível, incomensurável: a diferença da qual a autodemarcação parte não é dissolvida ou subsumida pela dobra que ali é realizada; a tensão não é 'resolvida', estabilizada. Antes, ela perdura, desdobrandose nas relações e nos arranjos engendrados em cada caso: entre os diferentes atores que deles participam (coletivos indígenas, órgãos estatais, ONGs, pesquisadores e outros); na formação ou na atuação de organizações indígenas; ou na participação de distintas agências, não apenas nas figuras de representantes, mas também na expressão de suas forças (como o Estado e o Mercado). Poderia parecer contraditório anunciar a incomensurabilidade como o centro desse encontro, não fosse ela a possibilidade mesma dele acontecer e de se estabelecerem, com ele, relações em que persistem (e resistem) a diferença. Em outras palavras, penso que para tomar a realização do processo demarcatório para si é necessário, para os índios, saber que a TI como categoria, como forma e modelo não equivale ao que a terra é para eles. Isto é: a terra indígena não se encerra, dissolve ou se reduz à TI; a tradução não é completa, pois prevalece a incomensurabilidade - índice de resistência. Caso contrário, seria apagada a diferença que anima e dá corpo à política.

Se a expressão da autodemarcação é a dissonância, a sua via é o dos equívocos controlados: um modelo de tradução em que a diferença é a condição para a significação, e não o seu obstáculo (Viveiros de Castro, 2004:20; ver também Herzfeld, 2001 e Lambek, 1998). Menos do que denotar apenas um simples problema de compreensão (pois o problema reside justamente em "entender que os entendimentos não são os mesmos", como coloca Viveiros de Castro), a ideia de equivocidade trata de um modo de comunicação no qual diferentes perspectivas se encontram em termos homônimos para distintos referentes (De la Cadena, 2010: 351). O objetivo dessa "disjunção comunicacional" é evitar perder de vista a diferença que reside nos homônimos equívocos, uma vez que os interlocutores não estão falando sobre a mesma coisa, e sabem disso (Viveiros de Castro, 2004:9). Não se busca resolver a disjunção, apagar a diferença contida na equivocidade e suprimir a distância entre os conceitos em contato, uma vez que é o próprio espaço da equivocidade que permite "o encontro de diferentes mundos" (Entreterras, 2017:59). Seguindo Michael Lambek, Viveiros de Castro afirma que a incomensurabilidade não só permite como justifica os esforços de comparação - esta, ao mesmo tempo a ferramenta analítica primária e o material bruto da antropologia (2004:4). O ponto fundamental na discussão do autor é a possibilidade de reconceituar a comparação a partir da equivocidade e do processo de tradução dos conceitos práticos e discursivos dos 'nativos' em termos do aparato conceitual antropológico - promovendo, em última instância, uma deformação desse aparato:

[T]raduzir é sempre trair, como o ditado italiano diz. Uma boa tradução (...) é uma que trai a língua de destino, não a língua de origem. Uma boa tradução é aquela que permite aos conceitos estrangeiros [alien] deformar e subverter as ferramentas conceituais do tradutor para que a intenção [intentio] da língua original possa ser expressada no interior da nova. (idem:5) 
Inspirada no trabalho de Marisol de la Cadena (2010) - que discute os usos de "natureza" e "cultura" (e mais especificamente as montanhas e o "patrimônio cultural") pelos movimentos indígenas nos Andes como "sites of equivocation" -, experimento estender o conceito de equivocidade para outros âmbitos em que se dão esforços de tradução e de produção antropológica, como as demarcações e as autodemarcações de TIs. Se já é reconhecido que os processos de demarcação (especialmente nas etapas de identificação das áreas, nas quais o antropólogo precisa apresentar a relação dos índios com a terra e argumentar sobre a tradicionalidade da ocupação nela) se dão a partir de traduções (Leite, 1999; Gallois, 1999, Havt, 2002), não é exagero afirmar que o mesmo aconteça nas autodemarcações. Aliás, por compreenderem procedimentos comuns que desembocam num mesmo objeto, ambas promovem passagens e produzem novos sentidos para a terra: da terra vivida e entendida na perspectiva e nos termos indígenas, para a TI consolidada no modelo e sob os códigos do Estado; da terra vista quando se olha pra baixo (como aludido na epígrafe deste capítulo) para a terra traçada em mapas e descrita em coordenadas; da terra sem fronteiras em sentido estrito para uma área com uma forma, cujos perímetros são marcados e monitorados.

A diferença que me interessa sinalizar ao pensar a autodemarcação a partir dos equívocos controlados está antes no plano do processo de fazer essas passagens - ou melhor, a adoção desses processos, a passagem para as passagens, por assim dizer - do que no 'produto' delas (a TI propriamente dita, ainda que ela mesma seja um equívoco, independente de ter sido criada por ação estatal ou por esforços indígenas). Ater-se ao 'produto', aos resultados, seria apagar a diferença primeira entre os processos empreendidos pelos índios e os requisitos, as técnicas e os procedimentos previstos pelo Estado ${ }^{8}$; ou seria, no mínimo, resumi-la ao âmbito desses procedimentos, como já discutimos aqui. O que busco fazer é deslocar a "disjunção comunicacional" para a determinação, por parte dos índios, de adotar um processo alheio de agir sobre a terra (de marcar, criar limites e, em muitos casos, até mesmo ocupar), processo esse que gera uma sobreposição de conceitos sabidamente distintos de 'terra'. Uma hipótese que tenho perseguido é a de que a dobra realizada pela autodemarcação faz com que o Estado, por sua vez, dobre-se sobre si mesmo (sobre suas próprias normas, seus conflitos e tensionamentos internos), tendo que 'lidar' com a TI que fora constituída sob o seu próprio regime. ${ }^{9}$

Para concluir o exercício de definição ao qual me ative até aqui, proponho tomar o termo "autodemarcação" menos no sentido de descrever modos de "participação' indígena na criação de TIs, ou de 'apropriação' dessa categoria pelos índios, ou de discernir 'graus' de autonomia desses grupos em relação ao Estado e a outros atores, e mais sob o enfoque do encontro entre perspectivas distintas

\footnotetext{
${ }^{8}$ E, nesse sentido, foco ainda na distinção entre pontos de vista sobre a terra (expressão de diferença ontológica), ao invés da distinção sociológica entre um grupo indígena e o Estado como entidade empírica, que pode se fazer presente, no processo de demarcaçã̃o, na figura de seus "representantes" (servidores públicos, consultores de determinado órgão etc.).

9 A discussão sobre o imbróglio em torno da regularização da TI Sawre Muybu, do povo Munduruku, no médio Tapajós ilustra bem esse ponto (cf. Molina, 2017a, Loures, 2017), uma vez que e autodemarcação realizada por esse povo teve o seu gatilho na declaração da então presidente da Funai Maria Augusta Assiratti, de que o processo de regularização fundiária daquela e de outras TIs munduruku encontrava-se parado por pressão de setores do governo interessados na construção do complexo hidrelétrico do Tapajós - que conta com uma usina, São Luiz do Tapajós, projetada para a área de uma das TIs. O reconhecimento dessa terra como de ocupação tradicional indígena, por parte do Estado, inviabilizaria a construção da usina, pois obrigaria o governo a remover os índios dali, o que é vedado pela Constituição de 1988. Ao demarcarem, eles mesmos, Sawre Muybu (seguindo a delimitação dos estudos técnicos realizados pela Funai), os Munduruku agem sobre o jogo de luz e sombra que permitia que o governo brasileiro fizesse de conta que não haveria Tis afetadas pelo "empreendimento".
} 
relacionadas à terra - conceitos, modos de agir, de habitar, de relacionar-se com ela etc. Experimento, assim, entender o radical "auto" como um indicador da transformação que ele exerce sobre o termo ao qual é acoplado; com isso, pode ser possível deslocar um problema com o qual me deparei ao iniciar este exercício: como traçar uma diferença entre demarcações 'convencionais' e autodemarcações sem deixar-se deslizar para a uma designação prévia do que um coletivo indígena poderia 'comportar', incorrendo na discutível operação de reificação do coletivo, grupo, povo ou sociedade indígena, já tão problematizada pela antropologia? Ou mesmo sem pretender colocar a questão em termos de 'graus' de autonomia ou protagonismo indígena (uma avaliação que certamente não cabe ao antropólogo fazer)? E como elaborar uma definição dessas iniciativas sem deixar-se capturar por um viés meramente técnico ou instrumental?

Ao abordar essas experiências a partir da dobra que elas realizam e da ideia de equivocidade controlada, deixando o termo a princípio 'vazio', permitimos que cada experiência fale por si: indicando como se deram, em cada caso, as passagens entre os diferentes registros de 'terra'; como cada povo lidou com o Estado, os seus códigos e o seu aparato burocrático; quais relações foram construídas nesses processos - e o que elas revelam sobre os modos indígenas de fazer política; e tanto mais. (E eu diria mais: abdicando da imposição de 'provar' o que há de realmente "auto", de propriamente "próprio" - para chegar a "genuíno" basta um pulo - nas experiências de autodemarcação, a etnografia se faz possível, abrimos espaço para o outro.) Observemos, então, quais são os casos identificados como "autodemarcação" no Brasil - reunidos no quadro abaixo, no qual se vê a localização das TIs, os períodos nas quais as autodemarcações se deram e indicações acerca do processo estatal de regularização fundiária.

\section{Considerações finais: além e aquém do Estado}

Por fim, faz-se necessário comentar o trato recente que autodemarcações e retomadas de terra receberam de João Pacheco de Oliveira Filho (2018). Ao abrir um dossiê sobre lutas por terra no Brasil - afirmando que a etnologia sulamericana das últimas décadas não investiu em reflexões sobre terra e território -, o autor lança uma espécie de programa de pesquisa que entende as retomadas como uma forma atual de territorialização ${ }^{10}$, ao mesmo tempo em que vincula as lutas indígenas à ideia de reelaboração cultural. Não é essa ideia ou o conceito de territorialização que examinaremos, vale notar: são os problemas da caracterização daquelas formas de ação política a partir desse esquema analítico, sobretudo no que diz respeito a resumi-las à pressão sobre o Estado-nação, ou mesmo a delinear limites temporais ao identificar autodermarcações e retomadas a determinadas formas de territorialização.

Para Oliveira Filho (2018), autodemarcações foram ações "individuais" e "isoladas" que ocorreram entre as décadas de 1970 e 1980, e cujo objetivo teria sido neutralizar entraves burocráticos à regularização de TIs (:12). Enquanto, para esse autor, essas iniciativas se limitaram a acompanhar os processos administrativos conduzidos pela Funai, as retomadas seriam algo de outra ordem: estando totalmente fora do rol de ações apoiadas pelo órgão indigenista ou por agências de cooperação internacional, esses processos de recuperação territorial romperiam com um "perfil de vítima” com o qual entidades ligadas a direitos

${ }^{10}$ Que não se deve confundir com territorialidade, como bem marcam Vieira et. al. (2015). 
humanos supostamente atuam (seja lá o que essa caracterização signifique), uma vez que os participantes das retomadas teriam - aí sim - posturas "militantes" e "protagonistas" (:13). Não há, por parte do autor, um investimento na caracterização dos termos por ele empregados, e portanto resta impreciso o sentido de "isolamento" ligado às autodetmarcações, ou de "militância", mobilizado a propósito das retomadas. Seja como for, a redução das autodemarcações à ação da Funai não se sustenta quando confrontada com as narrativas indígenas e as descrições etnográficas dessas experiências: ainda que também se configurem como respostas à morosidade na regularização fundiária, essas iniciativas transbordam a todo o momento os limites do processo administrativo - e evidenciam, sobretudo, um inequívoco "protagonismo" indígena, para usar os termos não só do autor, mas da extensa literatura que comenta a atuação dos índios nessas experiências.

Voltaremos a esse último ponto ao expor, ainda que resumidamente, algo dos casos que analisei na dissertação já citada. Nesse trabalho reuni em um quadro os casos de autodemarcações dos quais tive notícia na limitada produção acadêmica e jornalística sobre o assunto; se não o reproduzo aqui, é apenas por considerar realmente improdutiva qualquer delimitação desse conceito em extensão, ou mesmo uma distinção categórica entre autodemarcações e retomadas. Todavia, vale notar que autodemarcações também se deram após o período traçado pelo autor - que, inclusive, identifica a ação dos Munduruku como retomada, embora estes utilizem o termo autodemarcação e estejam notavelmente se esforçando em demarcar a TI Sawre Muybu: abrindo picadas no perímetro da TI, sinalizando os seus limites e monitorando-os (cf. Loures, 2017). ${ }^{11}$ Além disso, se considerarmos que há, já, uma espécie de consenso na literatura acerca da importância das retomadas para o nordeste indígena dos anos 1980 - como mostram Alarcon (2013), Tofoli (2010), Oliveira (2010), Bicalho (2010), por exemplo -, a fronteira cronológica estabelecida pelo autor revela-se algo descabida.

Embora seja especialmente inquietante a associação sugerida por Oliveira Filho entre autodemarcações e tutela, não residirá aí o foco deste comentário, considerando que o autor dedica-se menos a construir esse ponto do que a produzir a sua contrapartida: a identificação direta entre a conjuntura política atual e as retomadas de terra, que faria dessas ações uma "sexta forma de territorialização" (2018:12). Nosso esforço será, primeiro, o de observar as implicações de enquadrar as retomadas em um esquema que as vê sobretudo como uma "forma pós-tutelar de exercício da política pelos índios, implicando um modo diferente de conceber as suas relações com o Estado" (id.:13). Em seguida - e considerando que descrições dessas formas de ação políticas centradas na pressão sobre o Estado também são comuns no que diz respeito a autodemarcações, como vemos por exemplo em Neves (2012) -, experimentaremos outros caminhos analíticos. Pois ao contrário do que afirma Oliveiro Filho acerca de uma suposta ausência de reflexão sobre terra e território na etnologia americanista das últimas décadas (id.:2), partimos justamente de contribuições substantivas a esse campo (Gallois, 2004; Surrallés \& Hierro, 2004; Ladeira, 2007; Amoroso \& Mendes, 2013; Saéz, 2015; Vieira et. al., 2015; Entreterras, 2017; Morais, 2017) para pensar política indígena a partir da terra - mobilizando, para isso, autodemarcações indígenas e as dissonâncias de mão dupla que elas parecem produzir.

\footnotetext{
${ }^{11}$ Além do trabalho de Rosamaria Loures (que acompanhou de perto as ações dos Munduruku por anos) citado acima, ver também a cartilha que a Associação Pariri elaborou a respeito da autodemarcação, disponível online: http://media.wix.com/ugd/c99eo1_7dcfb3cedf6546869a9d9ac542ec73da.pdf . Acesso em 12/o9/2018.
} 
É mesmo digna de nota a ênfase que Oliveira Filho dá àquela suposta ausência e a certa insuficiência na reflexão sobre paisagem e territorialidade: a descrição das retomadas sob a noção de territorialização será justamente situada nesse espaço, sugerindo um ineditismo particular da proposta teórica a partir de confluência entre o fenômeno empírico (a emergência das retomadas como estratégia política no contexto atual) e a solução analítica (o investimento nas noções de terra e território). Ora, se o fenômeno não é exclusivo da conjuntura política atual, e nem é exatamente original a atenção à terra, a ênfase do autor provoca, no mínimo, algum estranhamento. De forma semelhante, o enquadramento analítico das políticas ameríndias que privilegia a ação estatal ou a relação dos índios com o Estado não só parece desconsiderar, em grande medida, os modos pelos quais esses povos encaram o aparato estatal no delineamento de suas estratégias políticas, ou como lidam com o que, no processo de regularização fundiária, escapa do mesmo aparato (como no caso da descrição das autodemarcações mencionada acima). A propósito, se os sentidos da terra, para os índios, não se reduzem à descrição da categoria de Terras Indígenas, não seria mais interessante questionar, antes, como os índios articulam essas diferentes noções de terra do que supor que um enquadramento analítico centrado na concepção estatal de território dará conta de definir essas ações políticas?

Esse enquadramento também passa ao largo de um notável acúmulo etnográfico acerca de aspectos outros das retomadas de terra, que não o da pressão sobre o Estado-nação. Em sua rica etnografia dos processos de recuperação territorial promovidos pelos Tupinambá da Serra do Padeiro (BA), Daniela Alarcon (2013) dedica considerável fôlego a argumentar contra essa redução: "Não desconheço que pressionar o Estado brasileiro para que concluísse o processo administrativo de demarcação da TI era uma das motivações dos indígenas ao realizar retomadas", começa a autora, criticando uma determinada leitura que Susana Viegas teria feiro da questão. "Penso, contudo, que, além de apresentarem esse componente instrumental, as retomadas traziam em seu bojo um leque de causas historicamente constituídas, que devem ser examinadas detidamente" (:54), segue Alarcon, mostrando que compõem esse leque de causas a crescente degradação do território; as ameaças contra a vida dos índios e os levantes contra a demarcação da TI; o intuito de promover plantios coletivos e nutrir as comunidades, solucionando problemas de desnutrição; a perspectiva de receber parentes que retornariam à terra; e razões afetivas diversas, ligadas à memória de violências e injustiças (:57). Com efeito, tanto o trabalho de Alarcon em sentido amplo, como a descrição de outras pesquisadoras que passaram pela região (cf. Ubinger 2012, Couto, 2008, Viegas, 2007), ou que atuaram em contextos semelhantes (cf. Cardoso, 2016) permitem vislumbrar um aspecto notável das retomadas de terra, que comentei com mais fôlego em outro lugar (Molina 2017b): a de condição para viver "de acordo com a cultura", como expressam os discursos indígenas em contextos distintos - pois terra é vida: é condição de autodeterminação ontológica e política. ${ }^{12}$

Que não restem dúvidas: não se trata de reivindicar um ou outro sentido da luta como anterior ao outro ou mesmo exclusivo; isso seria, no mínimo, improdutivo. Procuro, com a exposição anterior, fazer o movimento inverso: argumentar que também ali onde se buscar pressionar o governo pela regulariza-

${ }_{12}$ Nesse sentido, aproximações entre a etnologia produzida no nordeste indígena e em outros contextos de recuperação territorial podem ainda render contribuições potentes para uma reflexão sobre os sentidos de terra e de ação política indígena - como, por exemplo, na literatura notavelmente vasta sobre retomadas kaiowá e guarani em Mato Grosso do Sul, que inclusive já suscitaram reflexões sobre essas ações. Ver, por exemplo, Brand (1997), Crespe (2009, 2015); Pimentel (2012), Morais (2016), Cariaga (2019). 
ção de uma determinada área a luta é cosmopolítica. "Tem que pisar na terra para ter direito", disse uma mulher tupinambá a Alarcon, enquanto ambas olhavam fotos da primeira área retomada pelos índios da Serra do Padeiro - um direito que, conforme mostra a autora, "repousa nas determinações dos encantados" (2013b:121). Da mesma maneira que não é de qualquer sorte de direito ao qual se referia a tupinambá, não é de qualquer sorte de luta que falamos, mas da luta como forma de habitar a terra, habitar a terra como forma de luta. É do impacto dos conceitos indígenas de terra sobre o nosso conceito de política que se trata: eis o desafio para uma antropologia que se pretende aliada dos povos da terra.

Recebido em 12 de setembro de 2018.

Aprovado em 17 de abril de 2019.

\section{Referências}

ALARCON, Daniela F. 2013. O retorno da terra: as retomadas na aldeia Tupinambá da Serra do Padeiro, sul da Bahia. Dissertação (Mestrado). Programa de Pós-Graduação em Estudos Comparados Sobre as Américas. Brasília: Universidade de Brasília.

ALMEIDA, Alfredo W. B. 2008. Terras de quilombos, terras indígenas, "babaçuais livres", "castanhais do povo", faxinais e fundos de pasto: terras tradicionalmente ocupadas. 2 ed. Manaus: PPGSCA-UFAM.

AMOROSO, Marta \& MENDES DOS SANTOS. 2013. Paisagens Ameríndias, Lugares, Circuitos e Modos de Vida na Amazônia. São Paulo: Terceiro nome.

BARRETO FILHO, Henyo T. 2005 Disciplinando a diversidade cultural: uma perspectiva antropológica sobre a Portaria 14. In: SOUZA LIMA, A. C. \& BARRETO FILHO H. T., 2005. Antropologia e identificação: os antropólogos e a definição de terras indígenas no Brasil, 1977 - 2002. Rio de Janeiro, Contra Capa Livraria.

BICALHO, Poliene Soares dos Santos. 2010. Protagonismo indígena no Brasil: movimento, cidadania e direitos (1970-2009).

BRAND, Antonio. 1997. O impacto da perda da terra sobre a tradição kaiowá/ guarani: os dificeis caminhos da palavra. Tese de doutorado em História Íbero-Americana. Porto Alegre IFCH/PUC-RS.

CARDOSO, Thiago. 2016. Paisagens em transe: uma etnografia sobre poética e cosmopolítica dos lugares habitados pelos Pataxó no Monte Pascoal. Tese (Doutorado). Santa Catarina: Universidade Federal de Santa Catarina.

CLASTRES, Pierre. 2003. A sociedade contra o Estado: pesquisas de antropologia política. São Paulo: Cosac \& Naify.

COELHO DE SOUZA, Marcela S. 2009. Três nomes para um sítio só: a vida dos lugares entre os Kỉsêdjê (Suyá). Comunicação apresentada no IV Congresso da Associação Portuguesa de Antropologia. 
COUTO, Patrícia N. A. 2008. Morada dos encantados: Identidade e religiosidade entre os Tupinambá da Serra do Padeiro, Buerarema, BA. Dissertação de mestrado (Antropologia). Salvador, Universidade Federal da Bahia.

CRESPE, Aline. 2009. Acampamentos indígenas e ocupações: novas modalidades de organização e territorialização entre os guarani e kaiowá no município de Dourados - MS (1990-2009). Dissertação de mestrado. Dourados: FCH/UFGD.

2015. Mobilidade e temporalidade Kaiowá: do tekohá à reserva, do tekoharã ao tekoha. Tese (Doutorado em História-História Indígena)Universidade Federal da Grande Dourados, Dourados, MS.

DE LA CADENA, Marisol. 2010. Indigenous Cosmopolitics in the Andes: Conceptual Reflections beyond 'Politics'. In: Cultural Anthropology, Vol. 25, Issue 2.

ENTRETERRAS. 2017. 2017. v. 1, n. 1. Brasília: Laboratório de Antropologias da T/terra (T/TERRA)

GALLOIS, Dominique Tilkin. 200o. "Não sabíamos que existiam limites...". In: Catalogo Índios, nós. Lisboa: Museu de Etnologia.

2004. “Terras ocupadas? Territórios? Territorialidades?”. In: RICARDO, Fany (org.). Terras Indígenas e Unidades de Conservação da Natureza. O desafio das sobreposições territoriais. Instituto Socioambiental, São Paulo. . 2007. Gêneses waiãpi, entre diversos e diferentes. In: Revista de Antropoogia. vol.5o no.1 São Paulo.

2011. Terra Indígena Wajãpi: da demarcação às experiências de gestão territorial. São Paulo: Iepé.

GRAMKOW, Márcia M.; MELO, Guiomar; VIANNA, Fernando de Luiz B.; WENTZEL, Sondra. 2007. Antropologia, povos indígenas, cooperação internacional e políticas públicas no Brasil. In: SOUSA, Cássio N.; SOUZA LIMA, Antonio Carlos; ALMEIDA, Fábio V. R.; WENTZEL, Sondra. (orgs.). Povos indígenas: projetos e desenvolvimento Rio de Janeiro: Contra Capa Livraria

HERZFELD, Michael. 2001. Orientations: Anthropology as a Practice of Theory. In Anthropology: Theoretical Practice in Culture and Society. Michael Herzfeld, editor, pp. 1-20. London: Blackwell / UNESCO.

INGOLD, Tim. 1999. The concept of society is theoretically obsolete. In: INGOLD, Tim. Key debates in anthropology. London: Routledge.

JIMÉNEZ, Simeon \& PEROZO, Abel. 1994. Esperando a Kuyujani: tierras, leyes y autodemarcación. Encuentro de comunidades Ye'kuanas del Alto Orinoco. Caracas: Asociación Outro Futuro/ Gaia / IVIC.

KASBURG, Carola \& GRAMKOW, Márcia M. 1999. Demarcando Terras Indígenas: experiências e desafios de um projeto de parceria. Brasília: Funai; PPTAL;GTZ.

LADEIRA, Maria Inês. 2007. O caminhar sob a luz: território Mbya à beira do oceano: Unesp.

LAMBEK, Michael. 1998. "Body and mind in mind, body and mind in body: some anthropological interventions in a long conversation." In Bodies and Persons: Comparative Perspectives from Africa and Melanesia. Andrew Strathern 
and Michael Lambek, organizers, pp. 103-123. Cambridge: Cambridge University Press.

LEITE, Jurandyr C. F. 1999. A identificação de terras indígenas. In: KASBURG, Carola \& GRAMKOW, Márcia W. (org.) Demarcando Terras Indígenas: experiências e desafios de um projeto de parceria. Brasília: Funai; PPTAL;GTZ

LOURES, Rosamaria. 2017. Governo Karodaybi: o movimento Ipereğ Ayũ ea resistência Munduruku. Unpublished Masters thesis). Universidade Federal do Oeste do Pará Santarém, Brazil.

MEDINA, D. 2003. From keeping it oral to writing to mapping: the Kuyujani legacy and the De'kuana self-demarcation project. In: WHITEHEAD, N. L. (org): History and Historicities in Amazonia. Lincoln: University of Nebraska Press.

MENDES, Artur Nobre. 2002. O PPTAL e as demarcações participativas. SOUZA LIMA \& BARROSO-HOFFMANN (org.), Etnodesenvolvimento e políticas públicas; Estado e povos indígenas; e Além da tutela: bases para uma nova política indigenista. Rio de Janeiro: Contra Capa Livraria. p. 37-40.

MERZ, Martin. 1997. Auto-demarcação Madijá: um exemplo de iniciativa e competência dos povos indígenas da Amazônia. Rio Branco: UNI.

MIRAS, Julia T. 2015. De terra(s) indígena(s) à Terra Indígena. O caso da demarcação Krikati. Dissertação (Mestrado em Antropologia Social). Brasília: Universidade de Brasília.

MOLINA, Luísa Pontes. 2017a. Terra, luta, vida: autodemarcações indígenas e afirmação da diferença. Dissertação (mestrado em antropologia social). Universidade de Brasília.

. 2017b. Lutar e habitar a terra: um encontro entre autodemarcações e retomadas. In: R@U, 9 (1), jan./jun. 2017: 15-35.

MORAIS, Bruno. 2017. Do corpo ao pó. Crônicas da territorialidade Kaiowá e Guarani nas adjacências da morte. São Paulo: Editora Elefante. 362pp.

MORALES, Carlos \& QUISPE, María T. 2014. Teärime Siri’koi Aerime Suititi. El território Uwottuja. Bogota: Grupo de Trabajo Socioambiental de la Amazonia (WATANIBA)

NASCIMENTO, Sandra. 2016. Colonialidade do poder no direito e povos indígenas na América Latina: as faces da subordinação/dominação jurídica frente ao direito de retorno às terras ancestrais dos povos indígenas Kaiowá do Tekohá Laranjeira Ñande'Rú no Brasil e Mapuche do Lof Temucuicui no Chile. Tese de Doutorado. Universidade de Brasília.

NEVES, Lino V. 2012. Volta ao começo: demarcação emancipatória de terras indígenas no Brasil. Tese (Doutorado). Universidade de Coimbra.

NODARI, Alexandre. 2007. "a posse contra a propriedade": pedra de toque do Direito Antropofágico. Dissertação (Mestrado). Programa de Pós-Graduação em Literatura. Florianópolis: Universidade Federal de Santa Catarina.

. 2014. Limitar o limite: modos de subsistência. In: Os Mil

Nomes de Gaia: Do Antropoceno à Idade da Terra. Disponível em: < https://osmilnomesdegaia.files.wordpress.com/2014/11/alexandre-nodari.pdf> . Acesso em 23/09/2016. 
OLIVEIRA, Kelly Emanuelly de. 2010. Estratégias sociais no movimento indígena: representações e redes na experiência da APOINME. Programa de PósGraduação em Antropologia, Universidade Federal de Pernambuco, Recife.

OLIVEIRA FILHO, João Pacheco. 2018. Introduction. Vibrant. v. 15, n. 2.

PIMENTEL, Spensy (2012). Elementos para uma teoria política kaiowá e guarani. Tese de doutorado. São Paulo: PPGAS/USP.

SÁEZ, Oscar Calavia. 2015. O território, visto por outros olhos. Revista de Antropologia, v. 58, n. 1, p. 257-284, 2015.

SURRALLÉS, Alexandre; HIERRO, Pedro García (Ed.). Tierra adentro: Territorio indígena y percepción del entorno. IWGIA, 2004.

STRATHERN, Marilyn. Land: intangible or tangible property?. T. Chesters, p. 13-38, 2009.

TABAREZ, Jeymi 2011. Experiencia de autodemarcación de tierras multiétnica en el río Parucito, estado Amazonas. In: BELLO, Luis J. (ed.) El Estado ante la Sociedad Multiétnica y Pluricultural: Políticas Públicas y Derechos de los Pueblos Indígenas en Venezuela (1999-2010). Caracas: Grupo de Trabajo Socioambiental de la Amazonia (WATANIBA) pp. 87-96.

TÓFOLI, Ana Lúcia F. de. 2010. As retomadas de terras na dinâmica territorial do povo indígena Tapeba: mobilização étnica e apropriação espacial. Dissertação (Mestrado). Programa de Pós-Graduação em Sociologia. Fortaleza: Universidade Federal do Ceará.

UBINGER, Helen C. 2012. Os Tupinambá da Serra do Padeiro: Religiosidade e territorialidade na luta pela terra indígena. Dissertação de mestrado (Antropologia). Salvador, Universidade Federal da Bahia.

VIEGAS, Susana M. 2007. 2007. Terra calada: Os Tupinambá na Mata Atlântica do sul da Bahia. Rio de Janeiro, Editora 7Letras.

VIEIRA, José G; AMOROSO, Marta \& VIEGAS, Suzana de Matos. 2015. “Apresentação Dossiê Transformações das Territorialidades Ameríndias nas Terras Baixas (Brasil)”. Revista de Antropologia, São Paulo, USP, v. 58, nº 1.

VIVEIROS DE CASTRO, Eduardo. 2002. O nativo relativo. In: Mana8(2): 113148.

2004. Perspectival Anthropology and the Method of Controlled Equivocation. In: Tipit' 1. Journal of the Society for the Anthropology of Lowland South America. 2(1):3-22.

ZENT, Egleé L.; ZENT, Stanford; MARIUS, Leticia; HOTÏ de los caños Kayamá, Iguana, Majagua y Mosquito. 2003. Autodemarcando la Tierra: Explorando ideas, árboles y caminos Hotï. In: Boletín Antropológico. Año 21, $\mathrm{N}^{\mathrm{o}} 59$

ZENT, Egleé L.; ZENT, Stanford; MOLO, Lucas. 2011. Un largo y sinuoso camino: breve historia de la autodemarcación territorial Jodï en su décimo aniversario. In: BELLO, Luis J. (ed.) El Estado ante la Sociedad Multiétnica y Pluricultural: Políticas Públicas y Derechos de los Pueblos Indígenas en Venezuela (1999-2010). Caracas: Grupo de Trabajo Socioambiental de la Amazonia (WATANIBA) pp. 97-117. 